\title{
Aqueous suspension of carbon nanotubes enhances the specificity of long PCR
}

\author{
Zhizhou Zhang, Cencao Shen, Mingchun Wang, Han Han, and Xiaohong Cao
}

BioTechniques 44:537-545 (April 2008)

doi 10.2144/000112692

\begin{abstract}
DNA manipulation technology is facing more challenges in the postgenomics era. More and more nanomaterials have been investigated for their potential implications in developing better gene technology. In this study, we reported the beneficial effect of single-walled carbon nanotubes (SWCNTs) and multi-walled carbon nanotubes (MWCNTs) in enhancing the specificity and total efficiency of long (14 kb) PCR. Hydroxylic and carboxylic carbon nanotubes (CNTs) had similar enhancing effects. Nanotubes could become another component for improvements in the amplification of long DNA.
\end{abstract}

\section{INTRODUCTION}

A PCR target longer than 5-6 $\mathrm{kb}$ can usually be called long PCR. Long PCR has always been a problem for many laboratories of biomedical sciences worldwide. Although there are some commercially available long PCR kits, those kits often do not work for the amplification of specific long DNA fragments. There have also been some reports that describe protocols to improve the performance of long PCR (1-3), but in most cases, those protocols are very complex and not convenient to follow. Long PCR technology therefore has much room to improve. In practice, different approaches have to be tried before a long DNA fragment is finally able to be well amplified.

There are already a number of PCR enhancers, such as dimethyl sulfoxide, glycerol, formamide, betaine, singlestranded DNA binding proteins, and nanogold particles $(4,5)$. However, how to correctly use those enhancers for long PCR remains unclear. Recently, it has been suggested that single-walled carbon nanotubes (SWCNTs) can act similarly to $\mathrm{Mg}^{2+}$ ions in maintaining the high activity of DNA polymerase in PCR (6), but the potential effects of different types of carbon nanotubes (CNTs) on long PCR remain to be elucidated.

Long PCR has become increasingly important in the postgenome era, partially because genome technology, rather than simply gene technology, is experiencing some great technological challenges. No mature technology has been developed to easily amplify very long, say $100 \mathrm{~kb}$, DNA sequences, let alone GC-rich long DNA fragments. Long DNA manipulation technologies, including long PCR, are critical for cloning and other molecular manipulations of very long genomic sequences in functional genomics studies.

In this report, the effect of carbon CNTs on a long PCR system is explored. We amplified a 14-kb fragment from a $\lambda$ DNA template and found that CNTs significantly improved the amplification efficiency.

\section{MATERIALS AND METHODS}

\section{Carbon Nanotubes}

All CNTs [SWCNTs, multi-walled carbon nanotubes (MWCNTs), hydroxylic CNTs, or carboxylic CNTs (CNT-OH, CNT-COOH, respectively)] were purchased from TimesNano (Chengdu, China). The average outside diameters and product numbers are presented in Table 1. Sterilized distilled water was used to prepare all CNT suspensions with the final concentration of $10 \mathrm{mg} / \mathrm{mL}(\mathrm{w} / \mathrm{v})$. All CNT suspen- sions need to be ultrasonicated at $100 \mathrm{~W}$ for $1-2 \mathrm{~h}$ just before adding to the PCRs.

\section{PCR System}

In the long PCR system, primer P3 5'-TGGTTTATTGGAGTAGATGCTTG- ${ }^{\prime}$ and primer P4 5'-GAGAGTTGTTCCGTTGTGGG- $3^{\prime}$ were designed to amplify a $14.3-\mathrm{kb}$ fragment from $\lambda$ DNA. PCR reagents were mixed in a final volume of $25 \mu \mathrm{L}$ in $200-\mu \mathrm{L}$ thin-walled tubes according to the following conditions: $1 \times$ PCR buffer $(10 \mathrm{mM}$ Tris, $\mathrm{pH} 8.8$ at $25^{\circ} \mathrm{C}, 50 \mathrm{mM} \mathrm{KCl}, 0.08 \%$ Nonidet $\mathrm{P}$ 40, $2.8 \mathrm{mM} \mathrm{MgCl}$ ), $0.5 \mathrm{mM}$ dNTP, 0.35 $\mu \mathrm{M} \mathrm{P} 3$ and $\mathrm{P} 4,2 \mathrm{ng} / \mu \mathrm{L} \lambda \mathrm{DNA}, 0.1 \mathrm{U} / \mu \mathrm{L}$ Taq DNA polymerase, $0.05 \mathrm{U} / \mu \mathrm{L} P f u$ DNA polymerase, and the final volume was filled with aqueous suspensions of the CNTs and distilled water. PCR was performed on a T-Gradient Thermal block (Biometre, Göttingen, Germany) and/or a SpeedCycler (Analytik Jena AG, Jena, Germany). Initial denaturation at $92^{\circ} \mathrm{C}$ for $2 \mathrm{~min}$ was followed by 32 cycles of denaturation at $92^{\circ} \mathrm{C}$ for $20 \mathrm{~s}$, annealing at $63^{\circ} \mathrm{C}$ for $50 \mathrm{~s}$, and extension at $72^{\circ} \mathrm{C}$ for $15 \mathrm{~min}$. The final step was an extension at $72^{\circ} \mathrm{C}$ for $10 \mathrm{~min}$.

Trehalose (T5251) and betaine (B2629) were purchased from Sigma (St. Louis, MO, USA). $\lambda$ DNA, dNTP, Taq DNA polymerase, and $P f u$ DNA polymerase were from BBI (Markham, ON, Canada). Primers were synthesized 


\section{Research Reports}

from Sunbiotech (Beijing, China). All other DNA polymerases such as KOD Dash, DeepVent, and DeepVent (exo-) were purchased from Sangon (Shanghai, China).

\section{PCR Efficiency Assessment}

Three $\mu \mathrm{L}$ of PCR product were examined with $0.7 \%(\mathrm{w} / \mathrm{w})$ agarose gel with standard protocols. At the end of the electrophoresis, the gels were stained by ethidium bromide (Amresco, Solon, $\mathrm{OH}$, USA) with the concentration of $5 \mu \mathrm{g} / \mathrm{mL}$ in a $1 \times$ Tris-acetate-EDTA (TAE) solution (5). PCR product was photographed and quantitatively scanned by Gel Doc EQ (Bio-Rad Laboratories, Hercules, CA, USA). In all figures, molecular weight markers $(\mathrm{M})$ represented the same $\lambda$ DNA Marker ( $\lambda \mathrm{DNA} /$ HindIII) (Sangon, Shanghai, China).

\section{Preliminary Fidelity Assessment with DNA Sequencing}

A series of nanoparticles including MWCNTs and SWCNTs were used as PCR additives. PCR product was gelpurified followed by phenol/chloroform extraction and ethanol precipitation according to standard protocols. Purified DNA samples were sequenced with Sanger's method at Sunbiotech.

\section{RESULTS}

\section{CNTs Significantly Improve Long PCR Efficiency}

In this long PCR model system, we usually obtain nonspecific products, as manifested by smear bands in electrophoresis, even after adding a variety of PCR additives (data not shown). In order to get appropriate conditions of the $\mathrm{Mg}^{2+}$ concentration and the annealing temperature, betaine, a classical additive for long PCR, was applied in our model system as a starting condition. Annealing temperature gradients of $55^{\circ}-70^{\circ} \mathrm{C}$ with a fixed $\mathrm{Mg}^{2+}$ concentration of $2.8 \mathrm{mM}$, or various concentrations of $\mathrm{Mg}^{2+}$ from 2.3 to 5.3 $\mathrm{mM}$ with a fixed annealing temperature of $61^{\circ} \mathrm{C}$, were first tested as shown in Figure 1A. Based on these results, $61^{\circ} \mathrm{C}$ and 2.8 $\mathrm{mM} \mathrm{Mg}{ }^{2+}$ were chosen as the optimal

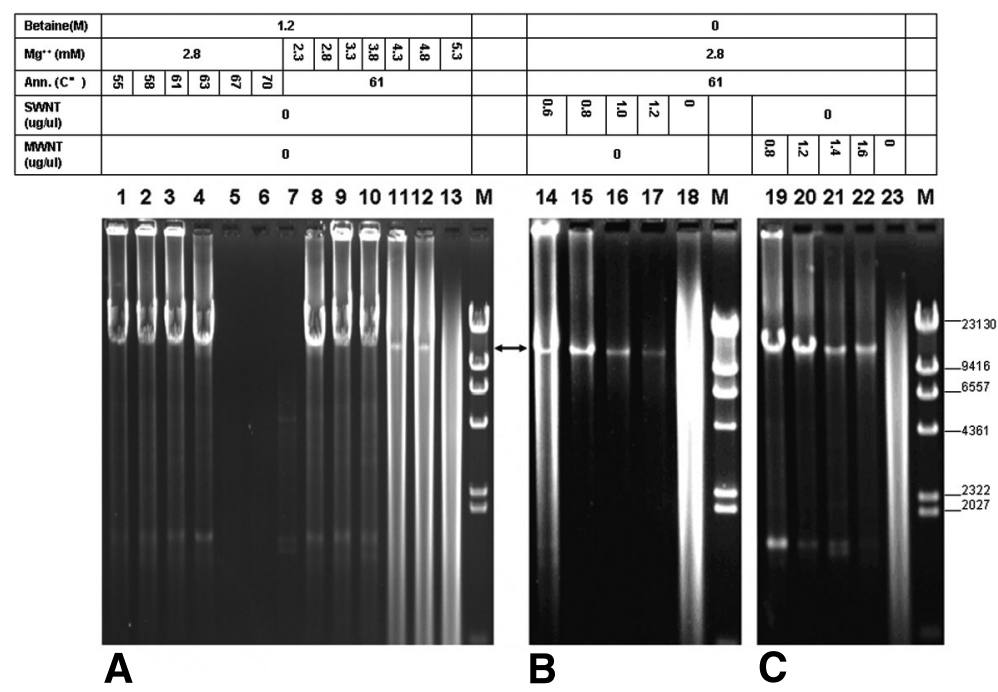

Figure 1. Carbon nanotubes (CNTs) significantly improved long PCR efficiency. Expected PCR bands are marked by an arrow. (A) Effects of $\mathrm{Mg}^{2+}$ concentration and annealing temperature in the presence of 1.2 M betaine without CNTs. (B) Effect of 1-2 nm single-walled carbon nanotubes (SWCNTs) on the specificity of PCR. (C) Effect of $<8 \mathrm{~nm}$ multi-walled carbon nanotubes (MWCNTs) on the specificity of PCR. M, $\lambda$ DNA Marker, $\lambda$ DNA/HindIII.

Table 1. Features and Catalog Numbers of CNTs Used in This Study

\begin{tabular}{|c|c|c|c|c|c|c|}
\hline \multirow{2}{*}{\multicolumn{2}{|c|}{ Outside Diameter }} & SWCNTS & MWCNTs & & & \\
\hline & & $1-2 \mathrm{~nm}$ & $<8 \mathrm{~nm}$ & $8-15 \mathrm{~nm}$ & $15-20 \mathrm{~nm}$ & $20-30 \mathrm{~nm}$ \\
\hline \multicolumn{2}{|l|}{ CNTs } & $\mathrm{S} 1212$ & M1201 & M1202 & M1203 & \\
\hline \multirow{2}{*}{$\begin{array}{l}\text { Functional } \\
\text { CNTs }\end{array}$} & $-\mathrm{OH}$ & SQ1213 & MQ1221 & & & MQ1225 \\
\hline & $-\mathrm{COOH}$ & SS1214 & MS1231 & & & MS1235 \\
\hline
\end{tabular}

CNTs, carbon nanotubes; SWCNTs, single-walled carbon nanotubes; MWCNTs, multi-walled carbon nanotubes.

parameters to test the effects of CNTs on long PCR (in absence of betaine). As shown in Figure 1, B and C, SWCNTs and MWCNTs had similar enhancing results. The serious smear bands significantly diminished, and the nonspecific trailing bands gradually disappeared by increasing the concentration of CNTs. An effective spectrum of concentration is $0.6-1.2 \mu \mathrm{g} / \mu \mathrm{L}$ for SWCNTs and $0.8-1.6$ $\mu \mathrm{g} / \mu \mathrm{L}$ for MWCNTs, which means that the optimal final concentrations of both SWCNTs and MWCNTs are close to $1 \mathrm{mg} / \mathrm{mL}$.

In this study, a total of 10 types of CNTs were tested (Table 1). Among them, six types were found to have apparent enhancing effects for long PCR. They were $1-2 \mathrm{~nm}$ SWCNTs, $<8 \mathrm{~nm}$ MWCNTs, $<8$ nm MWCNT-OH, 8-15 nm MWCNT-OH, 8-15 nm MWCNT$\mathrm{COOH}$, and 10-20 nm MWCNT-COOH. Among the above six CNTs, 1-2 nm SWCNTs and $<8 \mathrm{~nm}$ MWCNTs had slightly wider working concentrations than the other four chemically modified
CNTs (partial results are shown in Figure 2). We also noticed that CNTs had similar working concentrations $(\sim 1 \mathrm{mg} / \mathrm{mL})$ as carbon nanopowder, while another two nonmetallic nanoparticles (silicon nanopowder and graphite nanopowder) strongly inhibited PCR at the same concentrations (data not shown).

\section{Trehalose Helps Extend the Effective Concentrations of CNTs}

The above experiments all showed that PCR yield could drop dramatically when increasing the concentrations of CNTs. During the process of optimizing reaction conditions of CNT-assisted long PCR, we found that trehalose could maintain PCR yields to some extent over a wider concentration range of CNTs (Figure 3).

It has been known that trehalose greatly facilitates the PCR of GC-rich templates by reducing DNA melting temperature and thermostabilizing Taq DNA polymerase (7). It was also found that trehalose could greatly improve 


\section{Research Reports}

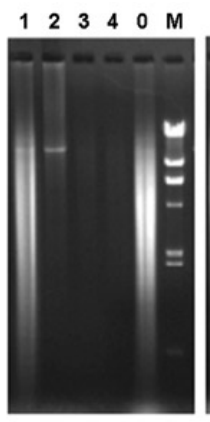

A

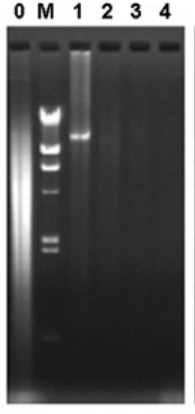

B

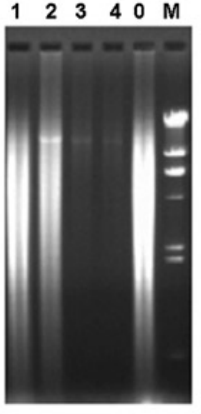

C

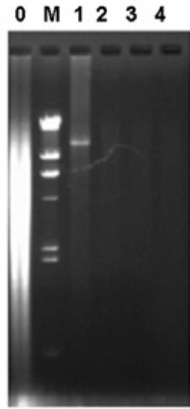

D

Figure 2. Effect of carboxylic multi-walled carbon nanotubes (MWCNT-COOH) and hydroxylic multiwalled carbon nanotubes (MWCNT-OH) on long PCR. From lanes 0 to 4 , the final concentrations of MWCNTs were $0,0.2,0.4,0.8$, and $1.2 \mu \mathrm{g} / \mu \mathrm{L}$, respectively. (A) $<8 \mathrm{~nm}$ MWCNT-OH, (B) $8-15 \mathrm{~nm}$ MWCNT$\mathrm{OH},(\mathrm{C})$ 8-15 nm MWCNT-COOH, (D) 10-20 nm MWCNT-COOH. M, $\lambda$ DNA Marker, $\lambda$ DNA/HindIII.

synthesis of long-chain cDNA (8). Our laboratory had previously found that trehalose could improve the overall long PCR performance when used together with several different nanoparticles, such as nanogold (data not shown). As shown above, this study found that CNTs improved long PCR efficiency only over a narrow range of concentrations. In a $25-\mu \mathrm{L}$ long PCR system, approximately $0.5-4.0 \mu \mathrm{L} 10 \mathrm{mg} / \mathrm{mL}$ CNT stock solution is the working range for most CNTs tested; even in this narrow range, the PCR yield could drop dramatically as shown in Figures 1 and 2. The addition of trehalose, however, leads to a relatively stable PCR yield with apparently improved specificity.

\section{CNTs: Enhanced PCR Does Not Compromise Fidelity in Preliminary Assessment}

An important goal of the research was to improve the fraction of the correct size DNA obtained by PCR. This goal was more important than the total amount of DNA obtained. However, it must be shown that fidelity is not impacted in these PCR transcriptions. We used the primers $\mathrm{P} 3$ and $\mathrm{P} 4$ and the purified $14-$ to $15-\mathrm{kb}$ PCR product in Figure 1 for sequencing tests. One of the sequencing results was shown in Figure 4, and it confirmed that the main DNA band amplified in Figure 1 was indeed the target DNA. Blast analysis (see the Supplementary Material available online at www.BioTechniques. com) provided preliminary indication that CNT-assisted PCR has similar fidelity of amplification as conventional PCR systems with Taq DNA polymerase. The preliminary fidelity assessment also included sequencing results using SWCNTs, MWCNTs, nanogold, nanoplatium, and carbon nanopowder (see the Supplementary Material). Basically, they had similar error rates as PCR without nanoparticles, but such end-sequencing of the PCR product is definitely not enough for fidelity determination. Systematic quantitative fidelity assessment needs further close examinations for nanoparticle (including CNT)-assisted PCR in the near future.

In this report, what we can say is that preliminary fidelity assessment solely by DNA sequencing of partial PCR product has not found any apparent differences between nanoparticle-assisted PCR (nanoPCR) and PCR without nanoparticles. This is good news, since the result may already be good enough to pave the way for nanoPCR to be used in thousands of laboratories. In the near future, we may find that a certain nanoparticle may raise the error rate of DNA amplification/replication to some extent, which would most likely be an environmental or molecular evolution issue and not a pure laboratory usage issue. If nanoPCR has a similar level of amplification fidelity as conventional PCR, in that at least a handful of (if not all) nanoparticles would not bring about fidelity problems, it will be directly useful in many laboratories.

\section{Effects of DNA Polymerase Combination}

The use of two DNA polymerases may overcome limitations that arise due to one enzyme's inability to incorporate opposite abasic sites (or other lesions) or to carry

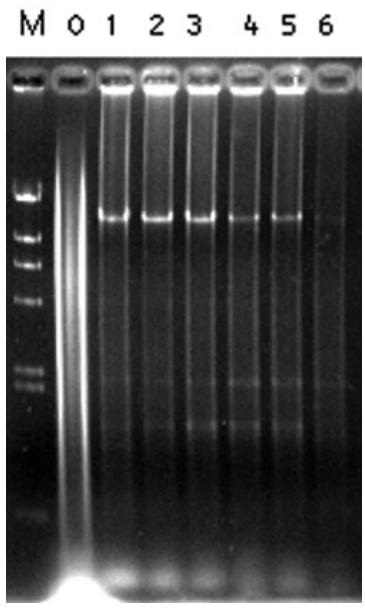

Figure 3. Trehalose helped to extend the effective concentrations of $<\mathbf{8} \mathbf{~ n m}$ multi-walled carbon nanotubes (MWCNTs) for long PCR. From lanes 0 to 6 , the final concentrations of $<8$ nm MWCNTs were $0,0.4,0.8,1.0,1.2,1.4$, and $1.6 \mu \mathrm{g} / \mu \mathrm{L}$, respectively. Trehalose was included in lanes 0-6 with a final concentration of $0.3 \mathrm{M}$. $\mathrm{M}, \lambda$ DNA Marker, $\lambda \mathrm{DNA} /$ HindIII.

out processive synthesis through regions of template secondary structure (9). The DNA polymerase blends described by Barnes contained no more than $20 \%$ Pfu (U/U), and optimal performance was achieved with blends consisting of $0.1 \%-$ $1 \%$ Pfu (2). Blends containing a higher proportion of $P f u$ exhibited reduced product yield and target-length capability, which Barnes attributed to the presence of excess $3^{\prime}$ to $5^{\prime}$ exonuclease activity. Therefore, a combination of different polymerases is useful, and worth trying, when a long DNA fragment is difficult to amplify. Figure 5 indicates that different combinations of DNA polymerases did yield large differences in the 15-kb DNA amplification.

We often found that significant materials were trapped in the wells, especially when performing long PCR. DNA trapped in gel wells could not be digested by restriction enzymes (Bam $\mathrm{HI}$ was used; the 15-kb target DNA has two Bam $\mathrm{HI}$ recognition sites), suggesting that it did not form a normal DNA duplex. Even after we purified the whole PCR product and refolded the DNA carefully, the gel-trapped DNA was still not digestible (data not shown). The DNA already running into the gel however was easily digested. This is related to incomplete extension and overextension (a too long extension when genomic DNA was 


\section{Research Reports}
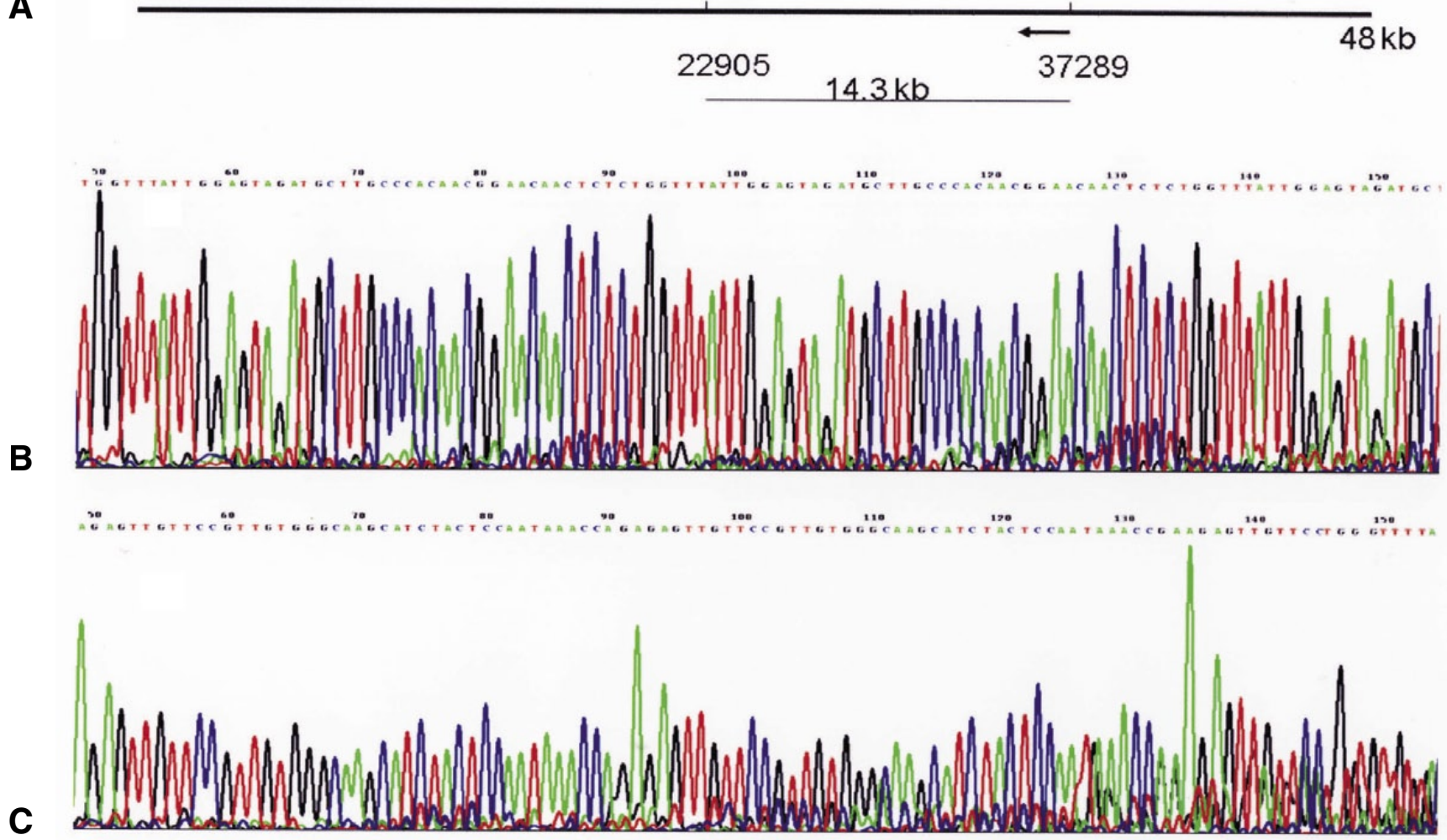

Figure 4. Confirmation of the product as the target sequence by DNA sequencing. (A) Product position in the $\lambda$ genome and sequencing strategy. Only two ends of the product were sequenced with primers P3 and P4, respectively, each with an effective reading of approximately 450-700 nucleotides (nt). (B) Part of the sequencing result with P3. (C) Part of the sequencing result with P4.

used as template for PCR). Also, long PCR renders DNA with a greater chance of heat-induced sequence changes, such as cytosine deamination, and such changes would complicate the process of a singlestranded DNA to double-stranded DNA (ssDNA-dsDNA) exchange.

\section{DISCUSSION}

A series of studies have been reported on carbon nanotubes in the context of their interaction with biomolecules and biological implications. For the first time, Cui et al. (6) presented their evidence that CNTs may bind to DNA polymerase and thus increase the activity and stability of the polymerase. Other evidence indicated that CNTs have an ability to enhance the activity and stability of some enzymes $(10,11)$. Yi et al., however, found that CNTs directly inhibit activities of Taq DNA polymerase and restriction enzymes, although detailed mechanisms need further investigation (12). Moreover, it was found that proteins could spontaneously bind to CNTs (13).
ssDNA could also spontaneously bind to CNTs in solution $(14,15)$. The above reports strongly suggest that primers and non-fully annealed DNA in a PCR system would likely bind to CNTs similar to ssDNA, and this would decrease the chance for primers to form incorrect duplexes (self-duplex or heteroduplex). However, once excess aqueous suspension of CNTs was added, the binding with more primers, together with the potential inhibitory effects on DNA polymerase (12), may result in low effective concentration of primers in the PCR system, thereby reducing the amount of PCR products.

The CNTs used here are hollow cylinders that consist of graphitic sheets wrapped into a cylinder and were initially discovered by Iijima (16) in 1991 with an arc discharge method. SWCNTs and MWCNTs are two basic CNTs, according to the number of their layers. As a novel material, in past decades, a large numbers of studies have been done to reveal remarkable electrical, mechanical, chemical, and thermal properties, which brought a wide range of application (e.g., nanobiosensor, energy storage tool, nanoprobe, and nanoelectronics). It has been reported that the thermal conductivity of individual MWCNTs measured at room temperature is high, up to 3000 Watts per meter Kelvin (W/mK), and the higher value of $6000 \mathrm{~W} / \mathrm{mK}$ for SWCNTs was obtained by Berber et al. (17). Although the thermal conductivity of the bulk of CNTs is lower than that of single CNTs, the reported minimum thermal conductivity is still higher than those of pure water and any nonmetallic liquid. When CNTs were dispersed in different phases, the measured thermal conductivity of the suspensions showed a remarkable enhancement in comparison with the dispersed phase as the working fluid (18-21). These suggest that the PCR amplification system with the added aqueous suspension of CNTs would have a higher thermal conductivity, making for a rapid thermal equilibrium and convection heat transfer. Therefore, the temperature of the PCR system is more uniform, and the time delay between the thermal block temperature and the sample temperature is also likely decreased. It 


\section{Research Reports}

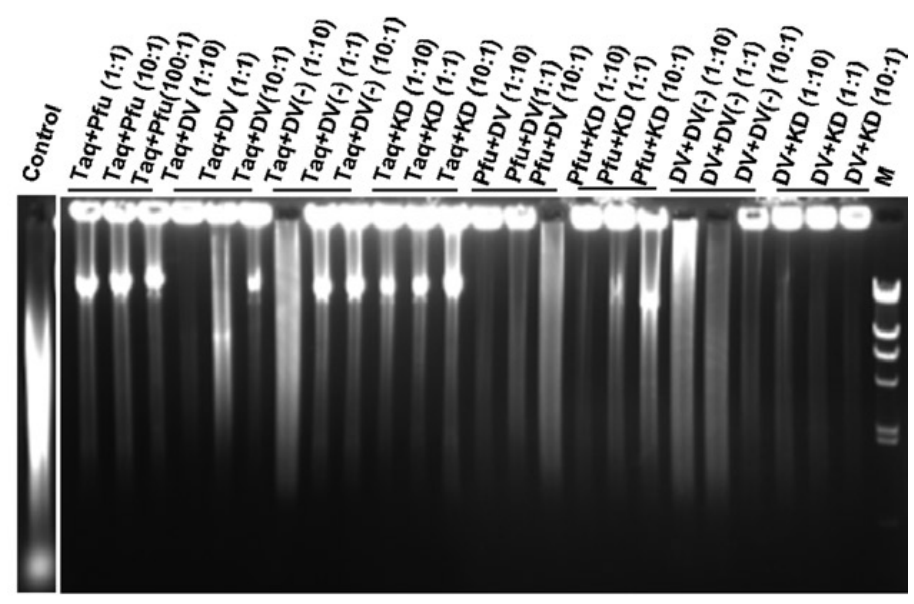

Figure 5. Differential effects of DNA polymerase combinations in multi-walled carbon nanotube (MWCNT)-assisted long PCR. Lane 1 (control), without any additive plus Taq:Pfu = 2:1; all other lanes with final $1.2 \mathrm{M}$ betaine and $0.4 \mu \mathrm{g} / \mu \mathrm{L}$ MWCNTs. Different lanes had different ratios (in unit) of two selected enzymes. DV, DeepVent; DV(-), DeepVent(exo-); KD, KOD Dash. M, $\lambda$ DNA Marker, $\lambda$ DNA/HindIII.

would be beneficial for PCR to increase the specific annealing of primers with templates, thereby lowering the chance of forming nonspecific or smear products.

In conclusion, we found that an aqueous suspension of CNTs led to the apparent improvement of long PCR specificity. Both SWCNTs and MWCNTs significantly enhance the specificity of long PCR with a compromised yield. The possible mechanisms could include the enhancement of heat equilibrium and the interaction of CNTs directly with reaction components. Many studies on the biophysical biochemical properties of CNTs, especially the biochemical implications of CNTs, need time to undertake. By now, at least six types of distinct nanoparticles have been investigated for their beneficial effects on PCR, and they were nanogold, nanosilver, carbon nanopowder, carbon nanotubes, nanoplatinum, and nano-alloys $(5-7,22,23)$. Although we have not been clear on any mechanistic insight to explain what is going on, the collected data are enough to suggest that nanofluid could be a novel platform to develop a new generation of recombinant DNA technologies.

\section{ACKNOWLEDGMENTS}

This study is supported by a 2006 NECT grant, the National Natural Science Foundation (no. 30570401), TUST Funds, and a Shanghai ChuanQi grant to Z.Z. We are very grateful for

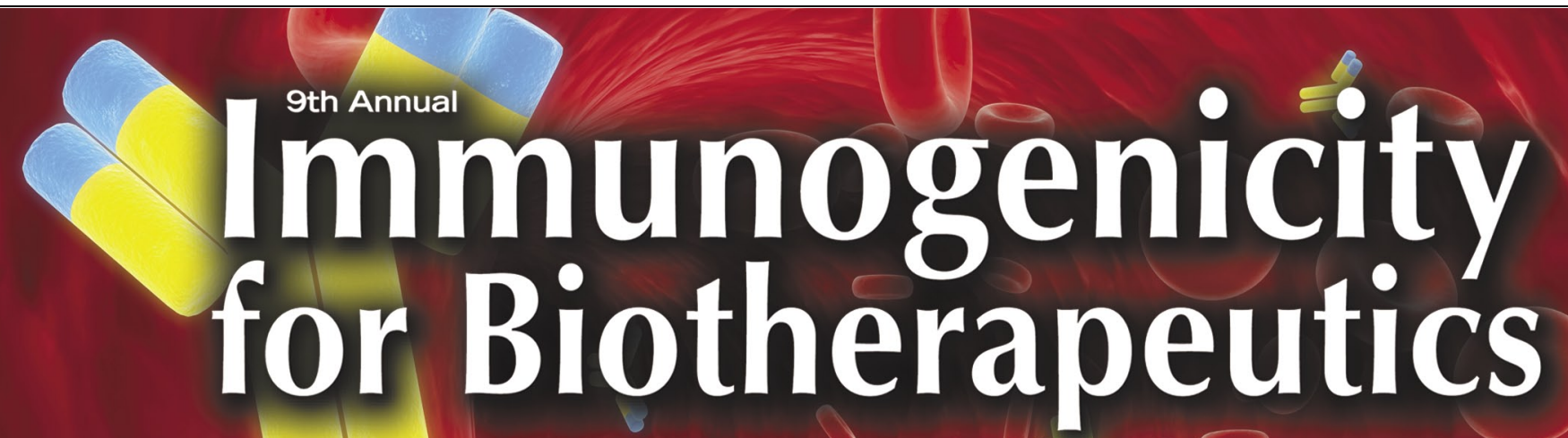

May 19-21, 2008 Hilton McLean Tysons Corner, McLean, VA
The largest Immunogenicity conference featuring ALL NEW Statistical Analysis, Assay Development and Validation, White Paper Updates, and Regulatory Considerations

\section{New for 2008:}

- 5 Industry Leaders Focus on FDA Regulations and New EMEA Guidelines

- FDA Invited to give their Perspective on Pre-Screening Protein Therapeutics

- 10 Case Examples of New Assay Development and Validation Strategies
- Talk Directly to the Authors of the New White Papers and Integrate the Most Recent Industry Practices into your $\mathrm{Lab}$

- New Immunogenicity 101 Pre-Conference Workshop - Learn the Basics from Industry Leaders 


\section{Research Reports}

comments and opinions from the reviewers and the editorial office.

\section{COMPETING INTERESTS STATEMENT}

The authors declare competing financial interests under pending China patent nos. 200610015470.0 and 200610016039.8.

\section{REFERENCES}

1. Barnes, W.M. 2003. Tips for long and accurate PCR, p. 53-60. In C.W. Dieffenbach, G.S. Dveksler (Eds.), PCR Primer: A Laboratory Manual, 2nd ed. Science Press, Beijing.

2. Barnes, W.M. 1994. PCR amplification of up to 35-kb DNA with high fidelity and high yield from $\lambda$ bacteriophage templates. Proc. Natl. Acad. Sci. USA 91:2216-2220.

3. Cheng, S., C. Fockler, W.M. Barens, and R. Higuchi. 1994. Effective amplification of long targets from cloned inserts and human genomic DNA. Proc. Natl. Acad. Sci. USA 91:56955699.

4. Henke, W., K. Herdel, K. Jung, D. Schnorr, and S.A. Loening. 1997. Betaine improves the PCR amplification of GC-rich DNA sequences. Nucleic Acids Res. 25:3957-3958.

5. Li, H., J. Huang, J. Lv, H. An, X. Zhang, Z. Zhang, C. Fan, and J. Hu. 2005. Nanoparticle PCR: nanogold-assisted PCR with enhanced specificity. Angew. Chem. Int. Ed. 44:51005103.

6. Cui, D., F. Tian, Y. Kong, I. Titushikin, and H. Gao. 2004. Effects of single-walled carbon nanotubes on the polymerase chain reaction. Nanotechnology 15:154-157.

7. Spiess, A.N., N. Mueller, and R. Ivell. 2004. Trehalose Iis a potent PCR enhancer: lowering of DNA melting temperature and thermal stabilization of Taq polymerase by the disaccharide trehalose. Clin. Chem. 50:1256-1259.

8. Spiess, A.N. and R. Ivell. 2002. A highly efficient method for long-chain cDNA synthesis using trehalose and betaine. Anal. Biochem. 301:168-174.

9. Eckert, K.A. and T.A. Kunkel. 1993. Effect of reaction $\mathrm{pH}$ on the fidelity and processivity of exonuclease-deficient Klenow polymerase. J. Biol. Chem. 268:13462-13471.

10. Gan, Z.H., Q. Zhao, Z.N. Gu, and Q.K. Zhuang. 2004. Electrochemical studies of single-wall carbon nanotubes as nanometer-sized activators in enzyme-catalyzed reaction. Anal. Chim. Acta 511:239-247.

11. Asuri, P., S.S. Karajanagi, H.C. Yang, T.J. Yim, R.S. Kane, and J.S. Dordick. 2006. Increasing protein stability through control of the nanoscale environment. Langmuir 22:5833-5836.

12. Yi, C., C. Fong, W. Chen, S. Qi, C. Tzang, S. Lee, and M. Yang. 2007. Interactions between carbon nanotubes and DNA polymerase and restriction endonucleases. Nanotechnology 18:025102.
13. Guo, Z., P.J. Sadler, and S.C. Tsang. 1998. Immobilization and visualization of DNA and proteins on carbon nanotubes. Adv. Mater. 10:701-703.

14. Zhao, W., Y. Gao, M.A. Brook, and Y. Li. 2006. Wrapping single-walled carbon nanotubes with long single-stranded DNA molecules produced by rolling circle amplification. Chem. Commun. 34:3582-3584.

15. Rajendra, J. and A. Rodger. 2005. The binding of single-stranded DNA and PNA to singlewalled carbon nanotubes probed by flow linear dichroism. Chem. Eur. J. 11:4841-4847.

16. Iijima, S. 1991. Helical microtubules of graphitic carbon. Nature 354:56-58

17. Berber, S., Y.K. Kwon, and D. Tomanek. 2000. Unusually high thermal conductivity of carbon nanotubes. Phys. Rev. Lett. 84:4613-4616.

18. Kim, P., L. Shi, A. Majumdar, and P.L. McEuen. 2001. Thermal transport measurements of individual multiwalled nanotubes. Phys. Rev. Lett. 87:215502-215505.

19. Eastman, J.A., S.R. Phillpot, S.U.S. Choi, and P. Keblinski. 2004. Thermal transport in nanofluids. Annu. Rev. Mater. Res. 34:219-246.

20. Yang, D., Q. Zhang, G. Chen, S. Yoon, J. Ahn, S. Wang, Q. Zhou, Q. Wang, and J. Li. 2002. Thermal conductivity of multiwalled carbon nanotubes. Phys. Rev. B. 66:165440.
21. Wen, D. and Y. Ding. 2004. Effective thermal conductivity of aqueous suspensions of carbon nanotubes (carbon nanotube nanofluids). J. Thermophys. Heat Transf. 18:481-485.

22. Wang, Q., J. Li, X.-H. Cao, and Z. Zhang. 2007. Silver nanoparticles enhance the specificity of repeated long PCR amplification. J. Tianjin Univ. Sci. Tech. 22:1-5.

23. Zhang, Z., M. Wang, and H. An. 2007 Aqueous suspension of carbon nanopowder enhances the efficiency of polymerase chain reaction. Nanotechnology 18:355706.

Received 26 July 2007; accepted 5 November 2007.

Address correspondence to Zhizhou Zhang, Teda Bio-X Center for Systems BioTechnology, Tianjin University of Science and Technology, Tianjin, China 300457. e-mail: zhangzzbiox@gmail.com

To purchase reprints of this article, contact: Reprints@BioTechniques.com

\section{MICROSCOPE AUTOMATION}

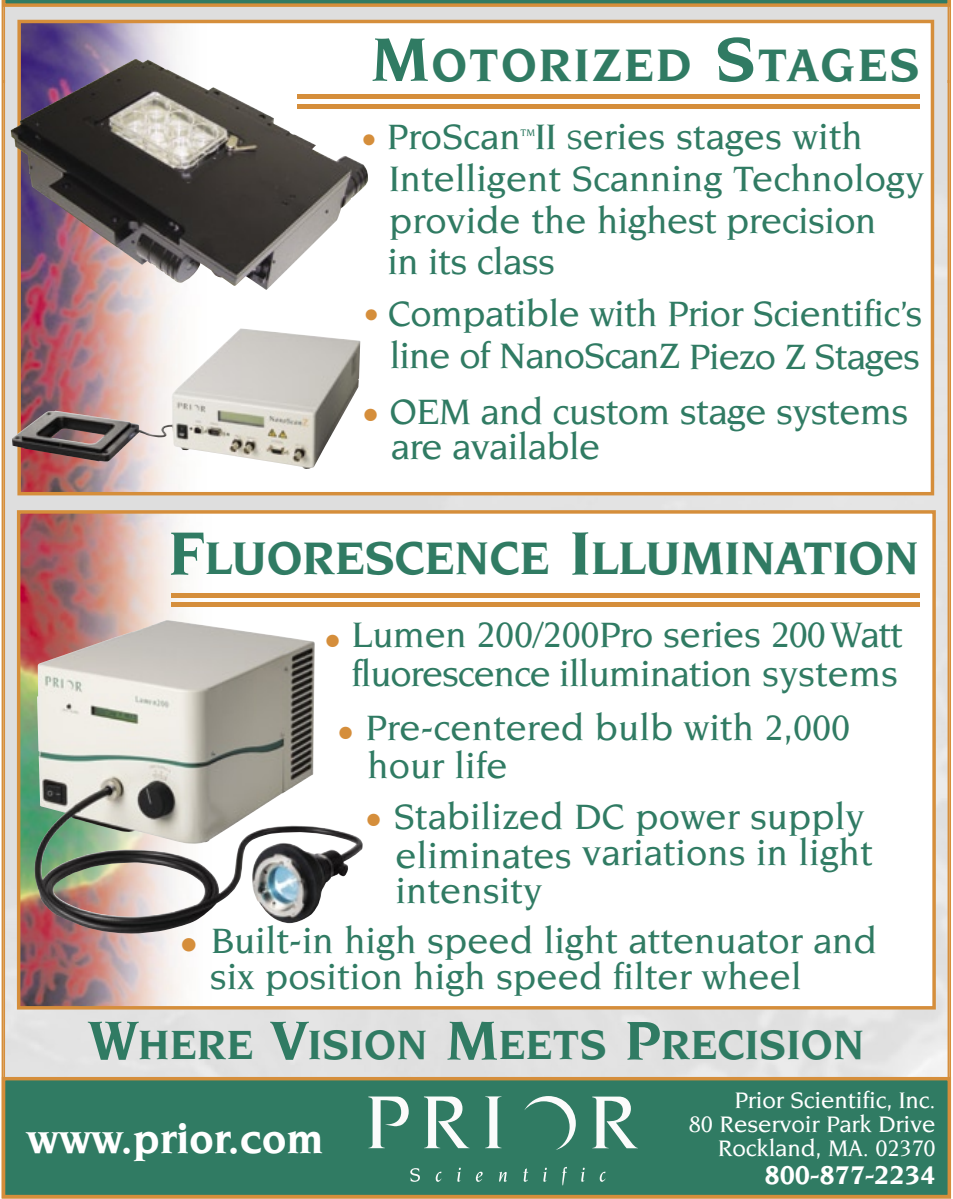

Circle Reader Service No. 183 